at least the essential scientific results of the expedition, some of which have already appeared, will be published before the end of 1956 .

The next paper is a contribution by B. C. Heezen, M. Ewing and E. T. Miller, of the Lamont Geological Observatory of Columbia University, New York, and deals with a "Trans-Atlantic Profile of Total Magnetic Intensity and Topography, from Dakar to Barbados". Early flights over marine areas with an airborne magnetometer indicated that correlation might exist between topographical features and the character of the magnetic field. By enclosing this instrument in a non-magnetic, streamlined, waterproof case, and towing it behind a ship, magnetic surveys of oceanic areas have become possible without the use of specially constructed, non-magnetic vessels, and the above authors give an account of such a survey across the Atlantic in 1948, when west of Dakar for 170 miles the magnetic field was found to be smooth with anomalies of less than 25 gammas. Anomalies of 50 to more than 200 gammas, 5-40 nautical miles in width, were encountered from the Cape Verde Islands region to Barbados. The topographical contrast between the deep ocean basins and the Mid-Atlantic Ridge was not reflected in the anomaly curve, while large anomalies observed over the submerged parts of the Cape Verde Islands showed the effect of known volcanic islands. No such anomaly was observed near Barbados, or over the continental margin of Africa.

A paper follows by F. Bermard on the role of calcareous flagellates in deep-sea fertility and sedimentation, as shown by recent work in the Atlantic Ocean and in the Western Mediterranean. Coccolithophorids were found to be the chief subscribers to sedimentation to depths of at least $4,000 \mathrm{~m}$., the total volume of calcareous flagellates generally amounting to more than 50 per cent, and often 95 per cent, of the phytoplankton in the bathypelagic zone.

Dr. Wiseman and $\mathrm{N}$. Hendry, from a unique bottom sample collected by H.M.S. Challenger in 1951, write on the significance and diatom content of a deep-sea floor sample from the neighbourhood of the greatest oceanic depth. The sample was from a depth of about $10,505 \mathrm{~m}$. at a position about five miles from the greatest known oceanic depth in the Marianas Trench ${ }^{2}$ and was taken by means of a Baillie rod. The position was about 60 nautical miles west of that at which, during her classical voyage of 1872-76, the former H.M.S. Challenger took a similar sample in about $8,185 \mathrm{~m}$. The two samples were similar in colour and of proportionately the same amounts of organically produced silica, but differed in the proportions of the organisms present, the earlier material being almost entirely composed of radiolarians with fow diatom fragments, while approximately 4 per cent of the recent sample consisted essentially of diatoms with minor amounts of radiolaria. There was clear evidence of erosion, the authors state, in electron microscope photographs of the 1951 sample. In conclusion of this article, the geomorphological relations and some of the problems of deep-sea trenches are discussed.

The concluding article to this interesting number of the new journal is one giving further notes on the greatest oceanic sounding and the topography of the Marianas Trench, by Dr. T. F. Gaskell, J. C. Swallow and Commander G. S. Ritchie.

J. B. TAIT

1 See Nature, 145, 306 (1940).

- See Nature, 189, 601 (1952).

\section{THE TRAVELLING SCHOLAR IN EUROPE BRITISH COUNCIL ACTIVITIES}

$T$ HE report which the British Couneil has issued*, with a forewortl by Sir David Hughes Parry, on a co-operative experiment in academic interchange between the universities of the United Kingdom and those of certain other European countries is a fitting complement, alike to the recent report on the Fulbright Programme (see Nature, 173, $1 ; 1954)$ and to the discussions on academic interchange within the British Commonwealth at the Congress of Universities of the British Commonwealth last July. The experiment began as the product of a cultural convention in 1946 between the Governments of the United Kingdom and of Belgium, and the British Council was designated as the principal agent of the British Government in the joint administration of the mixed commissions established to further the aims of this and similar conventions concluded between the United Kingdom and seven other European countries. The British Council entrusted its responsibility for carrying out recommendations regarding university interchange to its Universities Advisory Committee, with Sir James Mountford as chairman; but in 1950 a special standing committee, under the chairmanship of Sir David Hughes Parry, the vice-chancellor of the University of London, was constituted to deal with proposals for foreign university interchange.

As a result of discussions with representatives of universities and education authorities in seven European countries, it became clear that there was a widespread demand throughout Europe for the re-establishment and increase of academic contacts with the United Kingdom, and that two main types of visit were required : the short visit of a few days to a week to enable scholar to meet scholar for the exchange of ideas, to give one or two formal lectures or to participate in colloquia; and the longer teaching visit of up to a term in length. More recently, Belgium has voiced a desire for the interchange for short periods of younger university scientists who have not yet achieved an international reputation. Concentrating first on the short visit by teachers of established reputation, an agreed Foreign University Interchange Scheme with Belgium came into operation in 1948. This was followed by similar arrangements with the Netherlands and Norway in 1949; with France and Austria in 1950 ; with Western Germany, Italy, Spain, Sweden and Switzerland in 1951; and with Finland and Portugal in 1952; arrangements were also concluded with Yugoslavia for an interchange scheme to commence in the academic session 1953-54. In all, the Scheme provides for a total of fifty-four visits to United Kingdom universities from thirteen countries each session, and for a like number of visits by British university teachers to universities in these countries.

Since the first Scheme came into operation in 1948, 252 such visits have taken place between universities in the United Kingdom and in the other participating countries. While the principles of procedure vary

- University Interchange Between the United Kingdom and Other European Countries. 1948-1953. (A Report on Reciprocal Schemes which are in Operation Between the United Kingdom and Other Countries in Europe, for the Promotion of Interchange Visits by University Teachers, and for the Award of Scholarships.) Pp. 24. (London: The British Council, 1953.) 
slightly from one country to another, it has been proved that academic interchange can be organized centrally without undue threats to university autonomy and with economy in the administrative organization necessary. It is also clear that the short-period interchange visit meets a real need: no fewer than two hundred nominations are now received each year from United Kingdom universities for the incoming visits, and the number of invitations extended to British scholars by foreign universities leaves no doubt that the value of such visits is recognized just as fully by the other participating countries. Although some universities have independent schemes of their own which contribute to the total of interchange visits, it can be said that the Foreign University Interchange Scheme plays a substantial part in the renewal and furthering of academic contacts, with all that such contacts imply for international understanding and the advancement of knowledge.

Limited experiments have also been made in the provision of longer teaching visits. There are now four travelling lecturers attached to the French Institute in London who give regular courses at universities in the United Kingdom, and the British Council has to some extent met requests from abroad for similar teaching visits by British lecturers. Eight teaching visits for a month or more have been pæid by British university teachers to universities in Austria, Finland and France. While the value of the longer teaching visit has been amply demonstrated, the reduction of the British Council's grant-in-aid has necessitated the termination of such visits for the time being.

On a different level, the interchange of students for postgraduate study has also become well established as a two-way traffic. For a number of years the British Council has offered scholarships tenable in the United Kingdom to students from other countries throughout the world. During the five academic sessions under review, 410 awards have been made, mostly for postgraduate study at a university for one year, to students from European countries with which reciprocal scholarship schemes are in operation. In reciprocation, foreign governments and universities are now offering annually for postgraduate study in fifteen European countries more than a hundred such awards to British students, mostly for one year; and the British Council has been asked by these governments and universities to assist in the administration of the scholarships, and usually to arrange with the Universities Advisory Committee for convening selection boards to recommend suitable candidates. The large number of applications received indicates that the facilities are fully appreciated on both sides.

There are also certain direct exchange arrangements between universities in the United Kingdom and in other European countries, and scholarships and fellowships offered by individual universities add to the total volume of student interchange. While the immediate results of interchange at this level may be less apparent than with interchange at the teaching level, the first-hand experience gained provides a valuable cultural link between the United Kingdom and other countries. On the evidence of this report alone, reductions in the British Council's grant-in-aid, which compel the interruption of such interchange at all levels, are scarcely sound economy.

There is a further reason why the Government should take care to ensure that the British Council has sufficient financial resources to further interchange schemes on a reasonable scale. In December 1953, the Committee of Ministers of the Council of Europe signed in Paris five conventions, the most important of which will materially help young people from any of the sixteen member States in seeking admission to the universities of any of the others. The Convention commits the governments to the acceptance of international standards, but gives no guarantee of admission to a university, although the foreign student may be spared some troublesome examination when making application for admission.

The treaty powers are required to report progress in a year's time. No British Government either could or would attempt to dictate to the universities regarding the conditions or qualifications which the universities accept for admission, though British universities have been very unwilling to promise acceptance of equivalent qualifications of studies from outside the Commonwealth and the United States. Exceptions are in practice frequently granted, but both foreign students and officials are often perplexed by the apparent anarchy of regulations and variations from one university to another through which the wandering scholar has seldom shown much skill in finding his way. While the Government may well, particularly in view of the discussions at the Universities' Congress in July, expect the universities to give proof that they can really unite to make things easier for the individual student or scholar-who after all is nearer the wandering scholar or student of the Middle Ages than those whose movements are formally organized in interchange schemes-the Government must at least set the example of seeing that no short-sighted parsimony curtails what is already being done so admirably by the British Council and other bodies.

\section{THE NATURE CONSERVANCY}

$\Lambda \mathrm{N}$ article surveying the first two reports of A the Nature Conservancy*, covering the work of the Conservancy for the period up to September 30,1952 , and for the year ended September 30, 1953 , appears on p. 516 of this issue of Nature. Apart from their special scientific interest, they are of general interest as contributing to that wide understanding of the nature and importance of the work of the Conservancy which the Huxley Committee recognized as essential to the success of any system of nature reserves. Although the Nature Conservancy was constituted by Royal Charter "to provide scientific advice on the conservation and control of the natural flora and fauna of Great Britain ; to establish, maintain and manage nature reserves in Great Britain, including the maintenance of physical features of scientific interest; and to organize and develop the scientific services related thereto", the management (and still more the designation) of nature reserves demands a large amount of local co-operation and support. Even on the scientific side, the Conservancy recognizes that the full achievement of some of its essential tasks, such as a continuing thorough biological survey of the British Isles, requires a good deal of co-operation

* The Nature Conservancy. Report of the Nature Conservancy for the period up to 30 th September 1952 . Pp. iil +33 . 18. 3d. net. 1953. Pp. ii + 31. 18. 3d. net. (London: H.M. Stationery Office, 1953.) 